\title{
A devastating complication of long term indwelling catheter
}

\author{
W A S de Silva \\ Department of Urology, Teaching Hospital, Anuradhapura.
}

\section{Introduction}

Long term indwelling urinary catheters are commonly used in the management of spinal cord injured patients who are not candidates for intermittent catheterization. They are also used in elderly patients with retention of urine who are unfit for surgical intervention and as a part of palliative or terminal care. Long term use of indwelling urethral catheter (>30 days) can be associated with many complications like infection, bladder spasms, urethral erosion, hematuria, stones, epididymitis, urethritis, periurethral abscess, unprescribed removal, pain, fistula formation, obstruction secondary to encrustation, and leakage ${ }^{1}$.

\section{Case report}

52 year old male patient with a history of spinal cord injury following fall from a height more than 10 years ago presented to the urology consultation room complaining of continuous urine leak through perineum and damaged urethra. At the time of presentation he was on urethral catheter. He was initially on suprapubic catheter which was later converted to an indwelling urethral catheter by the local surgeon 5 years ago. He is wheel chair-bound following the accident.

On examination we found that his glans penis and the whole penile shaft were completely eroded and cleaved ventrally by the indwelling catheter (Figure 1). In addition to urethral split he had chronic, deep ulceration on ischio-rectal fossa (Figure 2) bilaterally communicating with prostatic urethra all of which had followed indwelling catheter according to him.

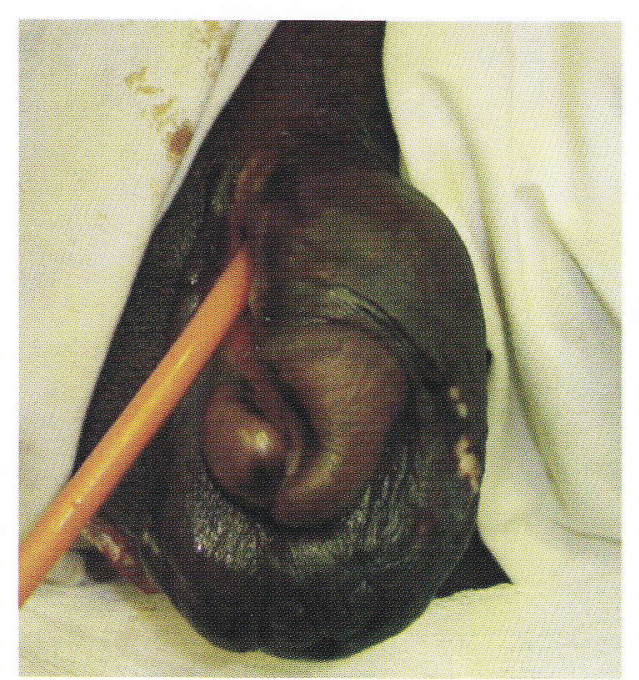

Figure 1

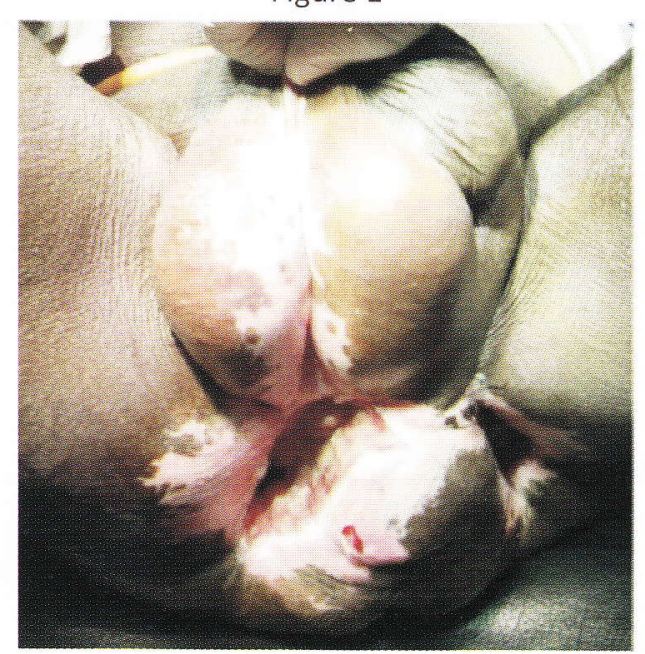

Figure 2 
Cystoscopy revealed a widely opened bladder neck and complete erosion into membranous urethra disrupting the sphincter mechanism and creating an urethro cutaneous fistula. He was initially managed with a suprapubic cystostomy but continuous urine leak and resultant soiling of chronic pressure sores compelled us to resort to surgical closure of the bladder neck.

\section{Discussion}

Among the other complications of long term indwelling catheter, urethral erosion is a challenge for the reconstructing urologist as the results are inferior to those with other urethral pathology and single operation does not usually solve the problem ${ }^{2}$. Mechanism of injury is by pressure necrosis caused by 1 . Improper size of Foley catheter 2. Improper technique of securing the catheter 3. Foley catheter balloon. Small caliber catheters should be used as large diameter catheters cause pressure on urethral mucosa and blockage of urethral glands resulting in necrosis, abscess formation and erosion. Foley catheter should be secured to the skin in such a way that it should be freely mobile without causing downward pressure by the urine filled bag which can result in iatrogenic hypospadias ${ }^{3}$. Improper placement of catheter in spinal cord injured patients with inflation of balloon within the urethra by untrained health care personals may result in urethral erosion and it is recommended that these patients should be catheterized by trained, senior staff. The best method to keep the bladder empty is to teach the patients on clean intermittent catheterization wherever possible.

2. J. T. Stoffel and E. J. McGuire, "Outcome of urethral closure in patients with neurologic impairment and complete urethral destruction," Neurourology and Urodynamics, vol. 25, no. 1, pp. 19-22,2006.

3. Andrews HO, Nauth-Misir R, Shah PJ. latrogenic hypospadias--a preventable injury? Spinal Cord. 1998 Mar;36(3):177-80. and Research; March 1996. AHCPR Publication No.96-0.682.

\section{Author}

- W A Susantha de Silva

Consultant Urological Surgeon, Department of Urology, Teaching Hospital Anuradhapura 